\section{Estratégias de atendimento aos casos de abuso sexual infantil: um estudo bibliográfico}

\section{Assistance strategies to sexually abused children: a bibliographical study}

Edinilsa Ramos de Souza 1 Simone Gonçalves de Assis 2 Fernanda de Carvalho Vecchi Alzuguir 3

1,2 Pós Graduação em Ciências. Escola Nacional de Saúde Pública. Fundação Oswaldo Cruz. Av. Brasil, 4036, sala 700. Manguinhos. Rio de Janeiro, Rio de Janeiro, Brasil. CEP 21.040-361

3 Universidade Federal do Rio de Janeiro

\begin{abstract}
This paper aims at an overview of international and national scientific work performed by health services related to sexually abused children. Analysis of 26 publications concerning the issue was performed focusing on the period from 1990 to 2000. Results indicated the predominance of international publications $(73,1 \%)$ and of reviews in the medical area $(38,5 \%)$. The majority of studies focused on specific assistance aspects, mainly on the diagnosis process whose central figure is the physician. The texts reveal the absence of an integral approach to this type of care. In addition to that, national publications tended to explore evidence denouncement and records.
\end{abstract}

Key words Child abuse, sexual, Health services
Resumo Este trabalho visa apresentar um panorama da produção científica nacional e internacional sobre atendimento a casos de abuso sexual infantil pelos serviços de saúde. Busca-se fornecer conhecimento sobre o assunto e subsídios para a melhoria do atendimento prestado. Efetuou-se uma análise das 26 publicações referentes ao tema, localizadas no periodo de 1990 a 2000. Os resultados revelam a predominância de publicações internacionais $(73,1 \%)$ e de revistas da área médica (38,5\%). A maioria dos estudos focaliza poucos aspectos do atendimento, abordando, sobretudo, o processo de diagnóstico cuja figura central é o médico. Os textos refletem a ausência de uma visão integral do atendimento. Constatou-se ainda nas publicações nacionais uma tendência a explorar a denúncia e o registro das evidências.

Palavras-chave Maus tratos sexuais infantis, Serviços de saúde 


\section{Introdução}

Um dos problemas que dificultam o planejamento de uma estratégia de atendimento adequada à realidade de vítimas de abuso sexual infantil é o desconhecimento da magnitude e impacto desse abuso. Smith et al.,1 em uma revisão bibliográfica das publicações de 21 países, confirmaram que o abuso sexual infantil é um problema internacional e que se estima sua prevalência entre $7 \%$ e $33 \%$ para mulheres e de $3 \%$ a $29 \%$ para homens.

Nos últimos anos, sobretudo a partir do movimento feminista, 2 tem-se reconhecido o abuso sexual como um problema social. Paulatinamente a atenção e preocupação transformaram-no em tema prioritário a nível internacional. Apesar dos avanços inegáveis, ainda se carece de pesquisas para melhor compreensão desse fenômeno. Alguns fatores contribuem para o pouco conhecimento do abuso sexual. Sanchez, citado por Ferreira, 3 identifica a existência de "sistemas de ocultação." Suas expressões vão do "complô do silêncio" por parte da família, que apenas revela o abuso quando o agressor é desconhecido; da vítima que esconde o abuso, às vezes durante anos, por medo e vergonha; passando pela contradição entre o papel esperado de apoio e proteção da família e a violência que se vivencia no âmbito doméstico, 4 até a rede social, cujas instituições não atuam de modo adequado. Um outro fator a destacar é o alto índice de subnotificação dos casos pelas instituições que recebem esta clientela, apesar da obrigatoriedade da notificação em vários países do mundo. Estes fatores evidenciam que o montante de casos registrados representa apenas uma parte do número real, 5 dificultando ainda mais a compreensão do fenômeno.

As instituições de saúde são, em muitos casos, o primeiro local de contato para o diagnóstico e tratamento. No entanto, tais instituições ainda não se encontram preparadas para uma abordagem adequada deste problema de caráter psicossocial. Os profissionais de saúde devem estar atentos para reconhecer os sinais e sintomas do abuso sexual, para romper com o ciclo de violência e ajudar às vítimas.

As instituições encarregadas de tratar o abuso sexual geram, às vezes, o chamado maltrato institucional que, segundo Casado, 6 engloba os atos de omissão, condições ou ações permitidas no contexto organizacional que ameaçam o desenvolvimento da criança. Fatores como escassez de pessoal, sobrecarga de trabalho e falta de apoio psicológico que permitam enfrentar diariamente estes casos, interferem de maneira importante no resultado do tratamento.

Diante das constatações acima e da necessidade de melhorar os serviços que atendem crianças sexualmente abusadas, o presente artigo é parte de uma pesquisa mais ampla que busca revelar o estado da arte da produção científica sobre o tema nos últimos dez anos. Tem como objetivo principal analisar a bibliografia sobre o atendimento institucional à crianças vítimas de abuso sexual pelos serviços de saúde, desde seu ingresso, as intervenções realizadas, até os encaminhamentos efetuados.

A relevância do estudo também se coloca a partir de outros fatores, dentre os quais destacam-se: 1) sistematizar o conhecimento sobre o atendimento prestado a esta clientela, a fim de fornecer subsídios para uma avaliação do nível de resolubilidade, eficácia e efetividade dos serviços de saúde e para a conseqüente melhora do atendimento; 2) buscar um maior conhecimento das estratégias de prevenção e atenção ao problema do abuso sexual na infância; e 3) necessidade de sensibilizar profissionais de saúde e sociedade civil para a gravidade do abuso sexual infantil e a importância do atendimento que prestam.

\section{Métodos}

A metodologia utilizada seguiu os princípios da pesquisa bibliográfica, envolvendo as atividades de identificação, compilação, fichamento e análise qualitativa das fontes bibliográficas, para o período de 1990 a 2000. As referências foram localizadas através das principais bases de consulta (Lilacs, Medline, Adolec) e fichas catalográficas das instituições visitadas.

As palavras-chave utilizadas na língua portuguesa foram: abuso sexual, violência sexual, atendimento, serviços, serviço de saúde, violência, criança, adolescente, estupro, incesto, enfermagem, serviço social, psiquiatria, sexual. Na língua inglesa foram: sexual abuse, health service, attendance, child, adolescent, rape, incest, child abuse, services, sexual.

Em razão da ausência de financiamento para a pesquisa, privilegiou-se o material bibliográfico existente em bibliotecas vinculadas à instituições que são referência em ensino e pesquisa no município do Rio de Janeiro, RJ, e em Niterói, Rio de Janeiro, Brasil.

A seleção das bibliotecas resultou na redução de material em relação ao total de fontes existentes sobre o assunto. Tem-se consciência da limitação deste levantamento. Entretanto, embora se saiba que o mesmo não é exaustivo em extensão, acredita-se que consegue realizar um aprofundamento da complexidade e das questões mais relevantes sobre a qualidade do atendimento e do funcionamento das instituições que atuam com crianças vítimas de abuso sexual. 
Para a pesquisa foram coletadas 178 referências nacionais e internacionais, em sua maioria publicadas em periódicos. Desse total, 50 referências foram selecionadas inicialmente sob algumas categorias que parecem refletir o processo geral de atendimento às vítimas de abuso. São elas: atendimento institucional; evidências clínicas e psicológicas do abuso; instituições específicas de atendimento; conceitualização de abuso sexual, e denúncia do abuso pelas instituições sociais. Acredita-se, como afirma Ferreira, ${ }^{3}$ que uma intervenção eficaz decorre diretamente de um diagnóstico competente, o qual depende da atuação adequada da equipe multiprofissional.

Diante da heterogeneidade dos temas, uma nova seleção foi feita, descartando-se 24 artigos que abordavam o abuso sexual de adultos, restando 26 artigos que tratam do atendimento prestado a crianças vítimas de abuso sexual, analisados no presente trabalho. Para o tratamento do material, utilizou-se a abordagem qualitativa através da "Técnica de Análise de Conteúdo", modalidade "Temática".? Procurou-se extrair os núcleos de sentido do material selecionado.

\section{Resultados}

\section{Aspectos gerais da produção analisada}

Os textos foram classificados segundo as metodologias utilizadas em cada publicação, ficando distribuídos da seguinte forma: estudos teóricos (textos voltados para a discussão teórica do abuso sexual), estudos epidemiológicos (análises da distribuição do fenômeno estudado em grupos ou locais específicos) e estudos clínicos (estudos fundamentados na análise de casos). Essa distribuição pode ser vista na Figura 1. Nela, verifica-se que a maior parte da bibliografia é caracterizada por estudos teóricos $(46,1 \%)$ e epidemiológicos $(42,3 \%)$, com número bastante reduzido de estudos clínicos.
Constatou-se que cerca de $73,1 \%$ desta bibliografia é internacional. Um dos fatores que explicam essa discrepância é o fato de se ter buscado, preponderantemente, bases de consulta internacionais. A esse fator, junta-se a escassez de estudos brasileiros a respeito do tema. A maior parte da produção científica analisada $(76,9 \%)$ está publicada em periódicos.

A partir dos títulos das referências classificaramse a(s) área(s) de conhecimento de cada publicação, objetivando identificar aquela(s) onde o tema está mais difundido, e o público alvo das publicações. Como se pode observar na Figura 2, um número significativo de publicações provém da área médica (aí incluídos os textos de medicina sem qualquer especificação da especialização, os da clínica médica e os de pediatria), seguida da área de saúde pública, psiquiatria, psicologia e enfermagem.

Figura

Distribuição da produção científica nacional e internacional sobre atendimento de casos de abuso sexual infantil, segundo a metodologia empregada, no período de 1990 a 2000

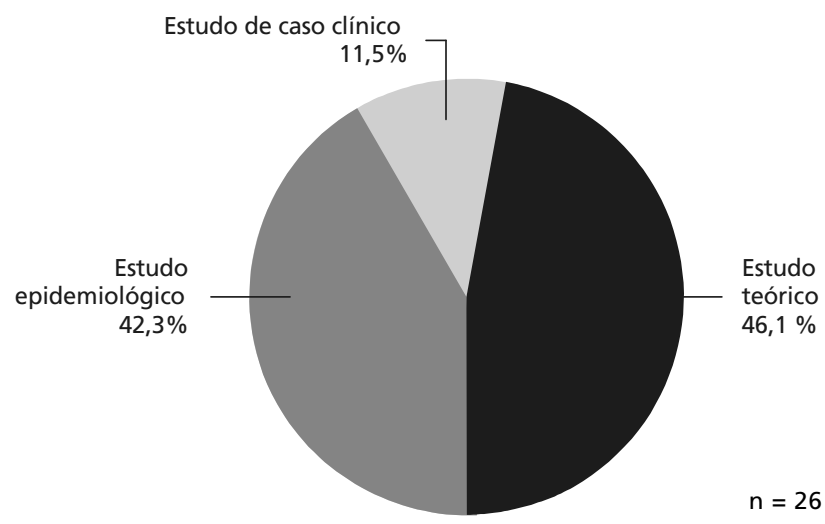


Para sistematizar o pensamento da produção científica sobre o atendimento institucional em relação ao abuso sexual infantil, optou-se pela estratégia de efetuar uma análise baseada no percurso da vítima nos serviços de atendimento. Assim, conforme se percebe na Figura 3, a literatura coletada foi subdividida nos seguintes itens: ingresso da criança no sistema de assistência; a denúncia do abuso; o processo de diagnóstico; e o tratamento psicossocial. Também foi incluída a capacitação dos profissionais que atendem casos de abuso sexual infantil. Essa última inserção se justifica pela influência da formação e treinamento dos profissionais na qualidade do atendimento prestado. Com exceção de uma publicação, 3 que abordou todas as categorias, os artigos tenderam a focalizar determinados elementos do atendimento. Deve-se destacar que, embora as categorias sejam aqui apresentadas separadamente, na prática, elas se encontram, muitas vezes, sobrepostas.

\section{Ingresso da criança sexualmente abusada no sistema de assistência}

A captação da criança no sistema de assistência e a revelação do abuso pela criança são temas abordados em seis dos 26 artigos analisados. De acordo com Ferreira, ${ }^{3} \mathrm{o}$ abuso sexual pode se apresentar aos serviços de três formas: como queixa explícita feita pela vítima ou acompanhantes, como suspeita a partir de um adulto, ou como causa subjacente de sinais e sintomas. Já segundo Tilden et al., 8 as vítimas se apresentam nas clínicas de tratamento pelos ferimentos e problemas de saúde associados ao estresse.

A emergência costuma ser a porta de entrada das vítimas de abuso sexual para os processos médicolegais. ${ }^{3}$ Dois estudos destacam as limitações desse serviço: é um local impróprio para entrevistas; dificilmente garante um atendimento tranqüilo ou ininterrupto para vítimas sem lesões agudas, e, segundo Gordon e Jaudes, citados por Ferreira, ${ }^{3}$ é inadequado ao atendimento das necessidades psicossociais da vítima; além disso é também, um espaço onde a coleta de evidências fica comprometida. 9

De forma geral, a bibliografia destaca que o funcionamento do serviço de emergência é compartimentalizado, em detrimento de uma abordagem integral à vítima do abuso sexual infantil.

No que concerne à revelação do abuso por parte da vítima, Tilden et al. 8 consideram que as vítimas de violência familiar tendem a não revelá-lo. O estudo de Campis et al. 10 conclui que a revelação, por parte de crianças em fase pré-escolar, costuma ocor-
Distribuição da produção científica nacional e internacional sobre atendimento de casos de abuso sexual infantil, segundo a área de conhecimento, no período de 1990 a 2000.

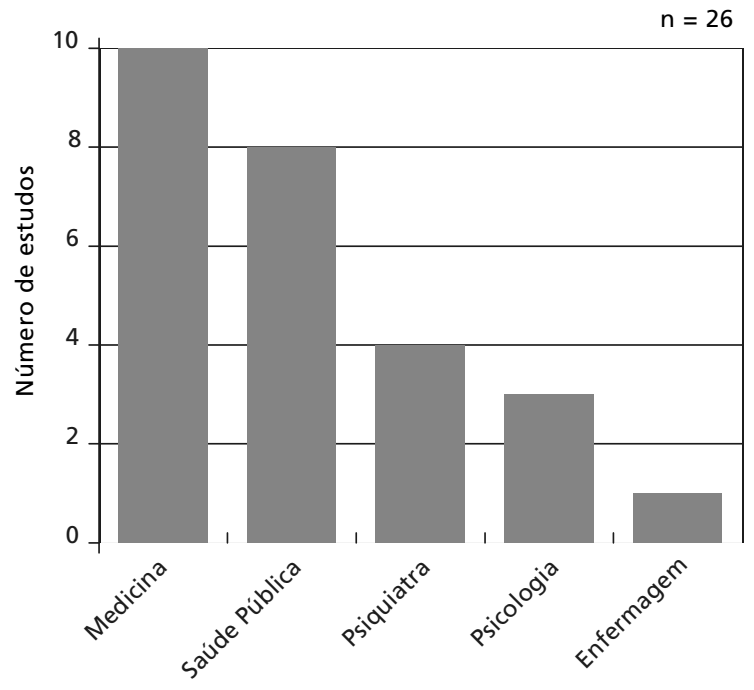

Figura 3

Distribuição das categorias que configuram o atendimento de casos de abuso sexual infantil.

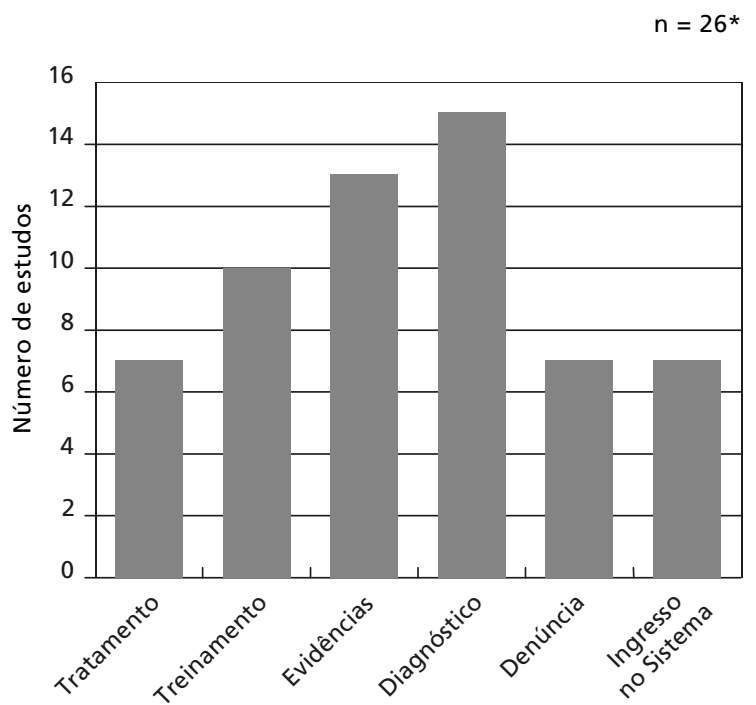

* Ha categorias sobrepostas no mesmo estudo 
rer de forma acidental e através de fatores precipitadores sem relação direta com o evento propriamente dito. São exemplos disso os sinais comportamentais que acabam denunciando-o. O estudo de Muram5 concorda que as crianças tendem a revelar o abuso de forma acidental e através de circunstâncias externas ao evento.

Campis et al.10 identificam que o tipo de revelação difere de acordo com a idade da criança. No caso daquelas em idade escolar, a revelação tende a ser proposital. Nessa fase também ocorre do abuso ser escondido deliberadamente, porque a criança passa a reconhecer a natureza tabu da sexualidade e a ter maior consciência das consequiências sociais da revelação. 11 Aqueles primeiros autores ressaltam o fato de que crianças mais velhas podem estar mais suscetíveis ao abuso sexual prolongado, devendo o profissional de saúde estar atento a isto. Jezierski ${ }^{9}$ relata um caso em que a terapia especializada e prolongada foi condição para o relato do abuso, por parte de uma menina, mostrando que a revelação não é necessariamente imediata ao ingresso da criança nos serviços hospitalares. Neste sentido, Torem et al. 12 destacam que indivíduos podem preferir relatar suas histórias de abuso em uma relação terapêutica.

A escola, ao contrário do que se coloca em relação ao serviço de emergência, é enfatizada como um ambiente no qual grande parte dos casos de exploração e abuso sexual contra este segmento é percebida. ${ }^{13}$

Flores et al., citados por Ferreira, ${ }^{3}$ constatam que $o$ atendimento de casos de violência doméstica por uma instituição é o índice de sua eficiência em localizá-los, tendo em vista o fato de que a violência na rua é mais explícita e identificável do que a doméstica.

\section{A denúncia do caso}

Neste item abordam-se as estratégias de notificação do abuso e os encaminhamentos das denúncias pelos profissionais.

Observa-se uma maior concentração de literatura nacional em relação ao tema da denúncia do abuso: cinco publicações e duas internacionais. $8,14 \mathrm{As} \mathrm{pu}$ blicações nacionais que se reportam a esse tema, revelam um aumento da denúncia, no Brasil, na última década. 3,4,15,16 As razões dadas para esse crescimento são o processo de articulação, a mobilização e experiências consolidadas no país, e a maior conscientização dos direitos da criança, da mulher e do adolescente. Ferreira ${ }^{3}$ aponta para um aumento de denúncias a instituições especializadas no Brasil, como a Associação Brasileira Multiprofissional de Proteção à Infância e à Adolescência (ABRAPIA), os
Centros Regionais de Atenção aos Maus-Tratos na Infância (CRAMI) e a Associação Brasileira de Prevenção aos Abusos e Negligências na Infância (ABPANI).

O aumento das denúncias aliado ao maior número de publicações nacionais sobre o tema decorrem da recente obrigatoriedade da notificação a casos de abuso sexual infanto-juvenil no país, a partir do Estatuto da Criança e do Adolescente (ECA), lei 8.069 de 1990. Em âmbito local, a Secretaria Estadual de Saúde do Rio de Janeiro determinou a obrigatoriedade da notificação dos casos de maus-tratos contra crianças e adolescentes, implementando ficha própria a ser utilizada em todo o estado. Desde então, as notificações passaram a ser encaminhadas aos Conselhos Tutelares e Secretarias Municipais de Saúde de todo o estado. ${ }^{3}$ Pesquisa de follow-up de algumas denúncias sobre exploração sexual de crianças e adolescentes realizadas pelo Disque-Denúncia da ABRAPIA, constatou que no estado do Rio de Janeiro, a maioria das denúncias é referida à Delegacia de Proteção à Criança e Adolescente (DPCA). Nessa delegacia, a apuração das denúncias se faz em duas etapas. Primeiro, verifica-se sua veracidade, conferindo-se os dados preliminares relativos ao caso. Segundo, confirmados os dados, instaura-se a chamada Verificação de Procedência da Informação (VIP)

A literatura norte-americana afirma a obrigatoriedade da notificação dos casos de abuso sexual infantil por parte dos profissionais de saúde às agências de proteção do estado. Bell et al. 14 em um estudo com 48 membros de hospitais que trabalhavam na emergência, constataram que procedimentos padronizados para relatar casos de violência interpessoal para agências do estado e encaminhamentos para serviços adicionais, tendem a ocorrer nos casos de abuso infantil e agressão sexual, áreas em que os hospitais são obrigados por lei a denunciar. Apesar dessa obrigatoriedade legal, uma questão corrente, narrada nacional e internacionalmente, é a subnotificação dos casos de abuso.

Em um estudo conduzido por Tilden et al.,, 8 constatou-se que a denúncia foi a intervenção mais raramente relatada entre os profissionais incluídos no estudo (dentistas, higienistas dentários, enfermeiras, médicos, psicólogos e assistentes sociais). Os assistentes sociais, médicos e profissionais do sexo feminino, foram os que mais relataram haver denunciado casos de abuso sexual infantil. Profissionais do sexo masculino preferiram lidar com os fatos sozinhos discutindo o problema com a família.

Ainda segundo esse estudo, o fracasso dos profissionais de saúde em notificar os casos de abu- 
so se deve à incerteza quanto à evidência clínica, apreensão quanto às ações dos serviços de proteção e medo de envolvimento nos tribunais. Santos, segundo Ferreira, 3 cita outros fatores como falta de conscientização social; desconhecimento das atitudes a serem tomadas; medo de revanchismo e dos transtornos legais ou acusação de falsa denúncia.

\section{O processo de diagnóstico}

O processo de diagnóstico foi dividido em dois subitens, a saber, a avaliação de evidências e o diagnóstico. O primeiro aborda os tipos de sinais indicativos/sugestivos do abuso e as estratégias de registro das informações colhidas. O segundo trata dos procedimentos de identificação ou suspeita de abuso sexual pelos profissionais de saúde ou do sistema legal, dos instrumentos utilizados, do tipo de informação que é privilegiada e da interpretação das evidências.

\section{Avaliação de evidências}

Metade das publicações analisadas (13) contribuiu para esta categoria. Dentre elas, os dois artigos que narraram sobre abuso sexual de meninos 17,18 revelaram que este tipo de abuso é comumente mais difícil de deixar sinais. O primeiro texto destaca como evidências, o relato do menino e a existência de vínculo à pedofilia. Já o segundo, evoca as lesões e hematomas na área anal. Roberts ${ }^{17}$ descreve a corrente preocupação dos pais de que o filho se torne homossexual em decorrência do abuso. Daí a necessidade de os médicos conversarem profundamente com os genitores.

No caso do abuso sexual contra meninas, dez artigos levantaram variados sinais físicos considerados indicativos do abuso pelos profissionais de saúde. Tais sinais se apresentam a seguir em ordem decrescente de freqüência com que são citados: lesões no hímen, corrimento, cortes, cicatrização, alargamento;18,19 confirmação laboratorial de doença venérea, marcas de mordidas na pele, cortes recentes ou cicatrizados na mucosa vaginal, que se estende à cavidade retal, e presença de esperma,3,5 lesões orais, periorais, na pele ou anogenitais, 2,3 sinais de violência física (hematomas, queimaduras), infecções anorretais ou orofaríngeas de etiologia possivelmente venérea; 2 e a presença de sangue, sêmen e cabelo do agressor no corpo da vítima. 20 Verifica-se que lesões no hímen e vaginais são os sinais mais destacados pelos autores, sendo necessário considerar a localização (meio, parte posterior da vagina) e o tipo de lesão (abertura alargada do hímen, cortes, cicatrizes) para realização de um diagnóstico correto.

Um artigo chama a atenção para outro indicativo de abuso sexual infantil, que são os objetos introduzidos na vagina como papel e plástico. Podem ser introduzidos pelos agressores ou até pelas próprias vítimas, como tentativa de fazer uma barreira para um novo abuso, aliviar a dor, parar o sangramento ou corrimento, ou obter controle sob o trauma. 21

Foram descritos em oito artigos os sinais comportamentais do tipo pesadelos, mudanças nos hábitos de dormir, comportamento muito apegado ao adulto, 5 brincadeiras agressivas ou sexualizadas com pessoas ou bonecos, 11 desenhos indicadores de ansiedade nos testes projetivos com figuras humanas, 22 estado emocional desproporcionalmente alterado, dados conflitantes de pacientes e dos demais envolvidos. 2

Loredo-Abdalá et al.,20 foram os autores que indicaram elementos comportamentais sugestivos de abuso bem distintos dos supra citados, destacando retardo mental, doenças crônicas e o fato da criança ser indesejada. Tais autores também levantam elementos de suspeita entre os familiares como alcoolismo, drogadicção, histórico de violações da lei, relações familiares rompidas e presença de padrasto. Três artigos descrevem condições que podem suscitar uma suspeita equivocada de abuso, que são as variações normais da genitália.5,17,23 Daí a importância do médico conhecer bem a anatomia prépúbere, 17,18 para evitar a realização de um diagnóstico equivocado. Esta preocupação revela a importância da formação profissional como variável relacionada à qualidade do diagnóstico.

Dos cinco artigos que abordaram o processo de registro das evidências coletadas para exame forense, destacam-se duas publicações nacionais 3,24 pela abordagem detalhada das informações necessárias para a elaboração de fichas de registro que sirvam de modelos para vários serviços hospitalares. Dentre essas publicações, ressalta-se a importância da norma técnica elaborada, em 1999, pelo Ministério da Saúde, e que constitui um valioso parâmetro oficial para avaliação da qualidade dos serviços no país. O estabelecimento de um modelo de ficha é importante para a padronização e análise comparativa dos dados. 24

Socolar citado por Ferreira ${ }^{3}$ descreve os dados essenciais para o registro dos casos de abuso sexual em geral: quem mora e quem cuida da criança; relação dela com o perpetrador; como ela o chama; onde, como e quando ocorreu o abuso; se foi utilizada força física; se o perpetrador e a vítima estavam vestidos; se algum tratamento foi realizado; se foi feito exame físico completo; descrição do hímen; 
qual o estágio de desenvolvimento sexual da criança, posição e técnica de realização do exame físico; presença de lesões penianas, escrotais, dilatação e lesões anais; qual o estado emocional da vítima. Zavaschi et al., citados por Ferreira, ${ }^{3}$ acrescentam informações sobre a duração do abuso; hábitos de vida da criança; uso abusivo de álcool e drogas na família; doença mental na família e modificações na conduta da criança. A Academia Americana de Pediatria recomenda, para o atendimento de vítimas de abuso sexual, um protocolo com os seguinte dados: história e exame físico, detalhamento de exames complementares, espaço para anotação do tratamento, notificação de um possível follow-up. Azevedo e Guerra, citados por Ferreira, ${ }^{3}$ propõem a composição de um "Dossiê diagnóstico multiprofissional" para o atendimento inicial das vítimas de abuso sexual, composto por ficha de abertura; acompanhamento do caso; laudo social; psicológico e do Instituto de Medicina Legal (IML); parecer síntese redigido por profissional responsável pelo processo; laudos ginecológico e psiquiátrico e boletim de ocorrência policial, sendo os três últimos, opcionais.

Há algum consenso de que o material deva ser guardado em um kit, lacrado, e assinado pelos profissionais que o manuseiam, de modo a garantir a "cadeia de evidência", condição fundamental para o julgamento. Aconselha-se o armazenamento em local inacessível ou trancado, para passar ao oficial de justiça, o qual também deve assinar o recebimento do material.5,24

Sugere-se o registro padronizado dos dados como uma forma do médico garantir a segurança médico-legal,17,25 além de atender às necessidades da criança e sua família. Esse último autor se destaca por ser o único a relatar que o pediatra deve discutir com a família e a criança o conteúdo apropriado para o relatório médico.

\section{Diagnóstico}

Esta categoria foi a que apresentou maior número de publicações (15), como se pode observar na Figura 3.

Normalmente é indicado o cotejamento de duas fontes para a identificação do abuso, quais sejam, o exame físico e o relato da história pela criança. Em alguns casos, percebe-se uma valorização maior da última fonte, sendo o argumento principal o fato de que o abuso sexual pode ocorrer sem deixar marcas físicas. Há também o argumento de que o uso isolado do relato como fonte de diagnóstico pode incorrer em erro devido ao falso relato ou a má interpretação dos fatos pelos adultos. 20 Berkowitz 18 sugere que a avaliação da criança vítima de abuso sexual deve constar de quatro partes: histórico médico (a fim de estabelecer o rapport com a criança e determinar a existência de condições médicas que possam explicar os achados); exame físico (inclui avaliação geral e específica anogenital), histórico psicossocial (inclui detalhes do abuso) e uma avaliação laboratorial para a investigação de doenças sexualmente transmissíveis (DST).

Há um conjunto de preocupações relacionadas à prestação de falsos relatos por parte de crianças não abusadas, que se mostram recorrentes em vários artigos. Quais sejam: evitar, no processo de investigação do abuso, seja no âmbito legal ou médico, perguntas fechadas e diretivas ${ }^{11}$ e repetições de perguntas por vários profissionais.5,26. Acredita-se que as duas situações podem conduzir a relatos falsos sobre o abuso ou causar dano à vítima.9,11,17 Também foram constatadas preocupações em relação ao uso de linguagem apropriada à faixa etária da criança entrevistada. $5,11,25$ e à capacidade da criança de distingüir entre fantasia e realidade. ${ }^{11}$ Em relação ao uso da linguagem, De San Lazaro25 atenta para o cuidado com o uso dos termos ao relatar os achados à criança.

Duas estratégias são propostas para equacionar a repetição de relatos do abuso pela criança para vários entrevistadores do sistema médico-legal, em diferentes momentos da investigação: 1) a gravação da entrevista em áudio e/ou vídeo, 200026 exceto quando a vítima se recusar ou se tais recursos tiverem sido usados no abuso; 2) a convocação coletiva de várias autoridades (polícia, agências de proteção à criança, entre outros), para testemunharem a entrevista com a criança. 9

Há opiniões diferentes a respeito do tipo de informação a ser colhida pelos profissionais de saúde na entrevista de diagnóstico, alguns autores sugerem a coleta de informação detalhada 5,26 e outros não vêem necessidade de uma entrevista profunda com a criança.17,19,25 Dentre esses, há consenso entre Houston et al. ${ }^{19}$ de que a investigação detalhada do relato não é papel do clínico geral. Ela deveria ser da competência de um assistente social treinado ou de policiais. De San Lazaro25 afirma ser normalmente suficiente para a anamnese, a obtenção de dados básicos relativos ao tempo, cronologia e sintomas diretamente relacionados ao trauma. Recomenda que se respeite a necessidade de privacidade da família e criança, perguntando se desejam conversar sobre o abuso naquele momento. Além disso, se deve perguntar à criança se ela própria deseja relatar o abuso. Caso não o queira, pede-se-lhe que nomeie um adulto para que assim o faça, sendo convidada a ouvir.

Muram ${ }^{5}$ defende a coleta de informação detalhada do abuso; para tal o entrevistador deve contar 
com o relato de parentes, oficiais de polícia, vizinhos e de outras crianças, caso ele, mesmo com técnicas complementares, não a consiga da própria criança abusada. Roberts 17 afirma que no processo de diagnóstico pode ser preciso cotejar informações de várias áreas como escolas, serviços sociais, polícia, e outras.

Os estudos que abordam os instrumentos que auxiliam o diagnóstico, voltam-se para a validade dos testes projetivos, $12,22 \mathrm{e}$ as "bonecas anatomicamente detalhadas". Autores concordam que a boneca deve ser usada por profissionais bem treinados e que seu uso isolado é insuficiente para avaliar se uma criança foi ou não abusada. 11,23

O jogo também foi destacado, com variadas justificativas, como um instrumento de auxílio ao diagnóstico Muram 5 afirma que tanto o jogo como as bonecas anatomicamente detalhadas são técnicas que têm sido desenvolvidas para superação das habilidades verbais limitadas de crianças pequenas. Também se considera que as crianças expressam-se melhor através dos jogos. ${ }^{26}$ De San Lazaro 25 afirma que o jogo, além de criar um clima de descontração e alegria, propicia ao pediatra a oportunidade de observar os temas enfocados, habilidades motoras e desenvolvimento da linguagem. De acordo com Sivan, citado por Koocker et al.,11 a experiência coletiva de gerações de clínicos e pesquisadores sugere que o jogo infantil normalmente reflete a realidade da experiência da criança.

Segundo De San Lazaro 25 e Roberts, ${ }^{17}$ o diagnóstico deve fazer parte do processo de restabelecimento da vítima. Nesse sentido, o artigo de De San Lazaro 25 merece destaque já que é o único que considera, de forma intimamente interligada, o restabelecimento psíquico da criança com o exame físico. Desse modo, o autor propõe uma abordagem calma, sem pressa e cuidadosa no exame físico e anamnese da criança, para que o exame não se torne uma outra forma de invasão. Acredita que o exame físico deve fortalecer e valorizar o self. Sugere que se mostre e permita à criança ver e tocar nos instrumentos de exame. Recomenda sua distração durante o exame anogenital, sendo elemento significativo para o processo de cura que se comente com a criança os resultados do exame. Outros artigos, no entanto, parecem segmentar as responsabilidades dos profissionais de saúde de modo a separar o processo terapêutico por um lado, do tratamento dos ferimentos e da identificação do abuso - funções estas que se mostram mais circunscritas à figura do médico. Ainda a respeito dessa segmentação de funções, Berkowitz 18 destaca que o médico da emergência deve se ater ao registro cuidadoso do exame físico e pedir ajuda a outros profissionais (especialmente os assistentes sociais), já que a criança requer um profissional com experiência em entrevistar.

Em vários textos, alguns procedimentos em relação à coleta de evidências mostraram-se, relativamente, semelhantes. Conforme Muram 5 tal coleta deve levar em consideração dois propósitos. Primariamente, atender às necessidades da vítima, e, secundariamente, coletar amostras que possam ser usadas como provas.

A estreita relação do atendimento hospitalar com a justiça perpassa em vários artigos. Uma autora ressalta que o profissional responsável pela coleta de provas pode ser uma importante testemunha do caso. No serviço descrito por ela, o profissional que é chamado a depor, é preparado pelo advogado distrital para assegurar-se de que o caso está bem preparado para o julgamento. Um outro examinador acompanha o colega para que não se sinta vulnerável. ${ }^{9}$

Nas publicações internacionais, médicos e enfermeiras parecem dividir a função de tratamento dos ferimentos da vítima com a de auxiliares da justiça, embora às enfermeiras também seja indicada a prestação de apoio emocional às vítimas. Há alguns autores, no entanto, que mostram visões diferentes a respeito do papel do médico. Esse, de acordo com Kini e Lazoritz, citados por Ferreira, ${ }^{3}$ deve decidir se existe suspeita do abuso, sendo essa decisão uma questão legal. A Associação Médica Americana recomenda aos médicos informarem às vítimas sobre a obrigatoriedade da notificação e a neutralidade de suas atitudes. ${ }^{3,18}$ De acordo com Heger, citado por Ferreira, ${ }^{3}$ o papel do médico consiste em assegurar à vítima e seus familiares que ela não é responsável pelo ocorrido e que ficará bem. Também deve encorajar os pais a manterem a criança em tratamento. É interessante notar a centralização das discussões unicamente na figura do médico em detrimento de outros profissionais.

Os instrumentos de coleta de provas correntemente citados são: a lupa, o colposcópio e a técnica de "wood's lamp" (raio ultravioleta que permite a verificação da presença de fluidos seminais no corpo da vítima em um quarto escuro). Independentemente do serviço, há consenso de que a coleta de evidência para exame forense é realizada caso a vítima se apresente no serviço até, no máximo, 72 horas após o abuso, sob pena das evidências se perderem. 5,18,20,27

Em relação ao ambiente para o processo de diagnóstico, Muram 5 afirma que a maioria das crianças pode ser avaliada em sala apropriadamente equipada para este tipo de exame, exceção feita aos casos que necessitam de sala equipada para operação e anestesia (normalmente em casos de penetração peniana), 
quando há um trauma significativo. A norma técnica elaborada no Brasil pelo Ministério da Saúde24 assinala o cuidado que se deve ter no sentido de evitar situações que possam promover o surgimento de estigmas, como setores identificados para atendimento exclusivo de vítimas de estupro. É importante que a entrevista seja feita resguardando-se a privacidade, estabelecendo-se um clima de confiança e respeito, e que os equipamentos e materiais, que devem estar em perfeitas condições de uso, confiram autonomia e resolubilidade à unidade.

Alguns autores narram de forma detalhada os procedimentos para o exame físico e entrevistas por parte do médico clínico. Em relação ao primeiro, as posições de colocar o joelho encostado na testa e deitada de bruços são consideradas favoráveis ao exame do hímen da menina.5,18 Três artigos descrevem que o procedimento de separação dos lábios da genitália da menina delicadamente para os lados ou o de submetê-los a uma leve pressão, são estratégias que permitem boa visualização do hímen.5,17,18

\section{A capacitação dos profissionais para o atendimento}

Alguns autores descrevem os sentimentos suscitados nos profissionais que lidam com crianças vítimas de abuso sexual como ansiedade extrema e desconforto, mecanismos de negação e de projeção, sentimentos de impotência e imobilismo - comuns aos que trabalham na ponta da rede de atendimento - forte mobilização e horror. ${ }^{3,4}$ De acordo com Junqueira, ${ }^{4} \mathrm{o}$ profissional que lida com este tipo de violência precisa não naturalizar os valores culturais que permeiam o registro sexual, e entender que o significado desse abuso encontra-se atravessado por um imaginário social e por leis jurídicas que condenam tal prática. A partir deste entendimento, é possível perceber os próprios sentimentos e cuidar da criança de forma consciente e positiva. Jezierski ${ }^{9}$ afirma que o sucesso do examinador depende dele sentir-se à vontade com sua própria sexualidade.

Nove referências $3,8,9,11,18,23,24,28,29$ destacam a necessidade de se promover treinamento para os profissionais. Apesar disso, apenas uma publicação brasileira, 24 descreve algumas técnicas de treinamento profissional, como: promoção de atividades que propiciem a reflexão da equipe sobre o tema da violência sexual, incluindo as técnicas de dramatização, vídeos, reuniões para esclarecimento.

Além do treinamento, há também duas publicações internacionais8,29 dirigidas à importância da educação de estudantes de disciplinas da área de saúde, cuja implementação tem influência na quali- dade do diagnóstico e na intervenção desses atores. Uma delas verificou correlação positiva entre educação sobre abuso e suspeita de abuso.

Os estudos de Muzychka 29 e de Tilden et al. 8 apontam para a necessidade da educação sobre violência constar no currículo de graduação médica. $\mathrm{O}$ primeiro, descreve o relato de um professor da área de violência familiar, de acordo com o qual, os estudantes de medicina ignoram como reconhecer o abuso e oferecer assistência; daí a importância da educação. Como estratégia para minimizar esse problema, alguns professores resolveram promover um simpósio para os estudantes de graduação e residentes de medicina, financiado pela escola de medicina, sobre o tema da violência familiar, que consistiu na promoção de aconselhamento para qualquer estudante que tenha a violência como tema de sua vida.

O estudo norte-americano de Tilden et al., 8 com 1.521 clínicos de várias disciplinas da área de saúde, constatou enorme carência nos programas de treinamento dos profissionais (um terço relatou nenhuma educação sobre violência familiar). Dos que informaram ter alguma educação, essa se concentrou mais no abuso sexual infantil (64\%). Psicologia e serviço social foram as únicas disciplinas em que a suspeita de abuso revelou-se mais alta.

A escassa produção científica sobre o assunto aponta para a necessidade de maiores estudos - internacionais e nacionais - sobre o tema da formação dos profissionais da área de saúde, já que tal tema possui importante influência na qualidade do atendimento.

\section{O tratamento}

Este item aborda as intervenções voltadas para os aspectos psíquicos e sociais das crianças e/ou das suas famílias, realizadas pelos profissionais de saúde, após diagnosticado o abuso, no âmbito hospitalar ou fora dele.

Se comparadas com as publicações sobre o processo de diagnóstico, categoria em que o exame físico mostrou-se sobrevalorizado, poucas foram as publicações (seis) que abordaram o tratamento psicossocial da criança vítima de abuso, mesmo assim, o fazendo-o de forma superficial.

Apenas em De San Lazaro25 verifica-se uma forma de abordagem diferenciada do médico pediatra no processo de diagnóstico, imbuindo o processo de coleta de evidências de uma perspectiva terapêutica com o objetivo de reduzir a ansiedade da criança, fortalecer o self e restaurar a auto-estima. $\mathrm{O}$ autor recomenda os seguintes procedimentos na anamnese: discutir com a criança suas preferências e doenças pregressas como forma de estabelecer uma conversa 
não intrusiva e um senso de importância e valor; fornecê-lhe a oportunidade para pintar ou modelar em outra parte da sala durante as perguntas. Sugere que, no encerramento da sessão, utilize-se de estratégias tais como o seu prolongamento através de lanche e jogo, a fim de evitar o desapontamento da criança.

Todas as seis publicações abordaram, em algum momento, o tema do tratamento psicoterápico de crianças vítimas de abuso sexual.3,4,5,13,26,28 Neles, afirma-se a possibilidade da realização do tratamento por parte dos familiares. Gauderer, citado por Ferreira, ${ }^{3}$ acha crucial o aconselhamento dos pais nos casos de abuso sexual infantil.

Apenas uma fonte 26 destaca os sentimentos ambivalentes dos pais da criança entre o querer amparar a família e a vítima e, ao mesmo tempo, necessitar de apoio para lidar com seus sentimentos de raiva e de culpa. Esse mesmo trabalho recomenda que os pais, antes de escolherem o tipo de tratamento, assegurem-se da existência de sistema de apoio próximio do local de moradia.

Deblinger et al. ${ }^{28}$ realizaram estudo a fim de verificar a eficácia do tratamento cognitivo comportamental para crianças abusadas sexualmente que contemplavam os critérios do Diagnostics and Statistical Manual of Mental Disorders-III (DSM-III) para distúrbio de estresse pós-traumático. Também ensinaram aos pais técnicas de resposta terapêutica às dificuldades comportamentais da criança, através da exposição, treinamento de prevenção e enfrentamento. A associação entre tratamento da criança e treinamento dos pais mostrou-se mais eficaz do que o tratamento da criança isolado.

O "Projeto Atender", 13 em Goiânia, foi o único exemplo, dentre as publicações analisadas, de serviço que realiza acompanhamento social às famílias de crianças e adolescentes vítimas de abuso sexual.

De acordo com o texto da American Professional Society on the Abuse of Children (APSAC), 26 a escolha do tipo de terapia (de grupo, individual ou terapia de família) será feita pela criança/família em função daquela em que se sentir mais à vontade. Cada uma delas possui suas vantagens: enquanto a terapia individual propicia privacidade ao cliente, a de grupo, dá oportunidades ao cliente de compartilhar sua experiência e aprender com os outros.

Muram 5 entende que o abuso sexual infantil requer um suporte diário intensivo. Para tanto, sugere uma intervenção ainda na crise, logo após o abuso ou revelação, seguida de um programa de tratamento de terapia individual ou de grupo.
Segundo a APSAC, 26 o processo terapêutico, no plano mais geral, pode ser dividido em duas fases: a avaliação, que identifica a extensão do trauma e delineia metas de tratamento, e o tratamento, que visa facilitar o processo de cura buscando alcançar as metas delineadas na avaliação. Em geral, o terapeuta deve explicar sua abordagem ao cliente. O tempo de terapia dependerá da complexidade do caso e das necessidades da pessoa naquele momento.

No estudo já citado de Deblinger et al.,28 os métodos utilizados nas 12 sessões individuais realizadas com 90 crianças vítimas de abuso sexual com distúrbio de estresse pós-traumático foram: exposição gradual (visando desfazer a associação entre ansiedade/vergonha e pensamentos relacionados ao abuso, através de repetida exposição a estes temas, para que respostas tranqüilas passem a se associar aos estímulos antes temidos), educação e prevenção do abuso sexual, enfrentamento (ajudando a criança a expressar de forma eficaz suas emoções e a lidar com a ansiedade). A avaliação antes e depois do tratamento constatou melhoras em todas as subcategorias do referido distúrbio.

Conforme Muram, 5 o terapeuta deve ajudar as crianças a lidarem com o processo investigativo e o tratamento médico. Segundo o autor, a maior tarefa dos terapeutas nestes casos consiste em fortalecer o ego, melhorar a auto-imagem e ensinar as crianças a confiarem nos outros e se sentirem novamente seguras. Esta abordagem mostra-se semelhante à de De San Lazaro. ${ }^{25}$ Para iniciar este processo, a criança deve compreender sua condição de vítima. Indo de encontro a esta acepção, Junqueira ${ }^{4}$ sugere uma abordagem psicoterápica, usando como base a noção psicanalítica de desamparo, e não somente da sexualidade, mudando o enfoque do atendimento psicológico que assinala a identidade de "vítima" ao paciente.

De acordo com Gauderer, citado por Ferreira, 3 todas as vítimas de abuso sexual beneficiam-se de intervenções em crise e acompanhamento por um ano ou mais, dependendo da gravidade do caso. $\mathrm{O}$ mesmo autor sugere a psicoterapia, inicialmente individual, seguida de psicoterapia em grupo, a qual propicia o apoio afetivo e identificação entre os participantes.

De acordo com Horowitz et al., citados por Ferreira, 3 o início precoce do abuso e a presença de depressão e comportamento delinqüente ou agressivo, são fatores preditivos para maior número de sessões de terapia para meninas abusadas sexualmente. 


\section{Discussão}

Algumas considerações a respeito da bibliografia analisada fazem-se necessárias. Primeiramente, trata-se da questão da articulação entre os profissionais de saúde que lidam com estes casos. Faltam publicações que assinalem a importância do trabalho de uma equipe multiprofissional em todo o percurso de atendimento das crianças vítimas de abuso sexual. Notadamente, apenas duas publicações nacionais 3,24 assinalam tal importância.

Acredita-se que esta articulação não deve estar restrita ao interior de cada serviço, mas deve também abarcar os diferentes serviços que prestam atendimento a esse tipo de clientela, de modo a conformar uma rede integrada de apoio. Para tanto, aposta-se na visão de Faleiros, citado por Ferreira, ${ }^{3}$ segundo a qual, a conexão dos profissionais em rede, depende de uma mudança na formação dos profissionais. Acrescenta-se aqui, a influência da formação dos profissionais de saúde na qualidade do atendimento a crianças vítimas de abuso, especialmente no processo diagnóstico. Esta formação deve ter como foco, a capacitação para a prestação de um atendimento mais sensível e adequado às vítimas desse tipo de violência, que inclui o abuso sexual infantil.

Verificou-se uma preocupação constante da produção internacional em delimitar o âmbito de ação das profissões, dando a impressão de uma fragmentação da atuação dos profissionais que lidam com vítimas de abuso infantil nos diferentes serviços de saúde. Tal preocupação parece explicar-se, em parte, pelo fato de muitos dos artigos internacionais analisados se destinarem especificamente a determinadas classes de profissionais, entre as quais destacam-se os médicos e os profissionais da área de saúde pública. Com algumas exceções, o papel do médico parece estar circunscrito ao levantamento de evidências físicas do abuso, cura dos ferimentos e notificação dos casos suspeitos aos órgãos competentes.

Refletindo a carência de uma visão sistêmica do atendimento a casos de abuso sexual infantil por parte das publicações, muitas delas - com exceção de Roberts 17 e De San Lazaro25 - revelam uma concepção do exame físico e anamnese como se estes não fizessem parte do processo de tratamento psíquico e social. Além disso, a preocupação com esse último mostra-se superficial e quase inexistente na literatura quer nacional quer internacional. Contrariamente a tal visão, acredita-se que além do tratamento das lesões físicas do abuso sexual, os profissionais devem tratar as crianças concebendo-as como um todo, de modo a incluir estratégias psicossociais de recuperação no processo de tratamento, co- mo recomenda De San Lazaro. 25 Para tanto, é necessário um diálogo constante entre os profissionais das diferentes áreas.

Chama a atenção a inexistência de publicações sobre o acompanhamento dos casos pelos serviços de saúde, após retornarem à comunidade. Essa é uma estratégia essencial ao restabelecimento psicossocial da criança vítima de abuso, reduzindo as chances de possíveis reincidências. Nesse aspecto, é importante entender que o processo de cura demanda um tempo e um espaço para além do âmbito dos serviços hospitalares.

Apesar da importância da integração entre os diferentes profissionais de saúde envolvidos dentro e fora dos serviços de assistência, observa-se uma necessidade de discutir melhor os papéis de cada um destes atores haja vista a centralização das funções no processo diagnóstico nas mãos dos médicos. Muitas vezes não fica clara a diferença entre médicos e juízes, no caso da literatura norte-americana. Isso é muito importante, face ao alto grau de poder que se costuma auferir ao saber e práticas médicas, poder este, que assume visibilidade nos textos analisados.

Um outro dado de suma importância refere-se aos procedimentos de registro dos casos atendidos. As fontes nacionais 3,24 propõem a padronização das fichas de atendimento, como forma de articular as informações entre diferentes serviços, e as internacionais 17,25 a dos relatórios técnicos, como forma de assegurar o cumprimento das obrigações legais. A padronização da informação gerada pelo registro, propicia vários benefícios entre os quais, a possibilidade de aumentar o conhecimento dos casos de abuso sexual infantil que dão entrada no sistema de saúde e a viabilização de planejamento de estratégias mais adeqüadas de avaliação dos serviços de atendimento. A subnotificação é um dos grandes obstáculos para uma maior compreensão do fenômeno e a uma conseqüente melhora no atendimento.

Assinala-se a maior ênfase das publicações nacionais em explorar o tema das denúncias e do registro, talvez em decorrência da recente oficialização da obrigatoriedade da notificação. Um maior conhecimento dos profissionais de saúde e da sociedade civil a respeito dos organismos locais e procedimentos de denúncia poderia ser um meio de diminuir este problema articulado com investimentos dirigidos a estes organismos com a finalidade de aumentar a resolutividade das denúncias e diminuir a desconfiança dos profissionais em relação à sua eficácia.

Cabe aqui destacar a constatação de que a maioria dos estudos epidemiológicos apresentou limitações 
metodológicas, particularmente no que se re-fere ao tamanho reduzido da amostra e sua localização em contextos específicos. Dessa forma, concluiu-se pela necessidade de estudos com amostras representativas da população de crianças vítimas de abuso sexual a fim de aumentar a fidedignidade dos estudos.

Por último, assinalam-se, mais uma vez, as limi- tações do presente levantamento bibliográfico, que não pôde realizar uma pesquisa mais aprofundada da literatura sobre atendimento a casos de abuso sexual infantil. Isso não impede, entretanto, que se tenha uma visão genérica do estado da arte da produção científica sobre o assunto.

\section{Referências}

1. Smith D, Pearce, L, Pringle M, Caplan, R. Adults with a history of child sexual abuse: evaluation of a pilot therapy service. BMJ 1995; 310: 1175-8.

2. Vitiello N, Coelho GA. Violência sexual contra crianças e adolescentes: critérios de suspeita. Femina 1998; 16: 1012-3.

3. Ferreira AL. O atendimento a crianças vítimas de abuso sexual: avaliação de um serviço público. [tese doutorado]. Rio de Janeiro: Escola Nacional de Saúde Pública da Fundação Oswaldo Cruz; 2002.

4. Junqueira MF. Abuso sexual da criança: contextualização. Pediatr Mod 1998; 34: 432-6.

5. Muram D. Child sexual abuse. Obstet Ginecol Clin North Am 1995; 17: 372-5.

6. Casado, DM. Niños maltratados. Madrid: Diaz de Santos; 1997.

7. Bardin L. Análise de conteúdo. Lisboa: Ed. 70; 1979.

8. Tilden VP, Schmidt, TA, Limandri, B, Chiodo, GT, Garland MJ, Loveless, PA.. Factors that influence clinicians assessment and management of family violence. Am J Publ Health 1994; 84: 628-33.

9. Jezierski M. Profiles sexual assault nurse examiner: a role with lifetime impact. J Emerg Nurs 1992; 18: 177-9.

10. Campis LB, Hebden-Curtis J, Demaso DR. Developmental differences in detection and disclosure of sexual abuse. J Am Acad Child Adolesc Psych 1993; 32: 920-4.

11. Koocker GP, White, C.S, Sivan AB, Goodman, GS, Friedrich, WN, Reynolds, CR. Psychological science and the use of anatomically detailed dolls in child sexual-abuse assessments. Psychol Bull 1995; 118: 199-222.

12. Torem MS, Gilbertson A, Light V. Indications of physical, sexual, and verbal victimization in projective tree drawings. J Clin Psychol 1990; 46: 901-5.

13. Notícia da criança $2000 ; 2: 1-4$

14. Bell CC, Jenkins EJ, Kpo W, Rhodes H Response of emergency rooms to victims of interpersonal violence. Hosp Community Psychiatr 1994; 45: 142-6.

15. Associação Brasileira Multiprofissional de Proteção à Infância e à Adolescência (ABRAPIA). Pesquisa de follow up de denúncias selecionadas sobre exploração sexual de crianças e adolescentes: relatório de pesquisa. Rio de Janeiro: ABRAPIA; 1999.

16. III Encontro do Plano Nacional Contra a Violência Sexual Infanto-Juvenil; junho 2000; Natal Rio Grande do Norte.
17. Roberts R. Knowing when to suspect child sexual abuse. Practitioner 1994; 238: 782-6.

18. Berkowitz CD. Pediatric abuse: new patterns of injury. Emerg Med Clin North Am 1995; 13: 321-41.

19. Houston A, Launer J, Roberts R. Suspected child sexual abuse. Practitioner 1990; 234: 747-50.

20. Loredo-Abdalá A, Trejo HJ, Bustos VV. Resident documentation of diagnostic impression in sexual abuse evaluations. Clin Pediatr 1999; 38: 9.

21. Herman-Giddens ME. Vaginal foreign bodies and child sexual abuse. Arch Pediatr Adolesc Med 1994; 148 195-200

22. Hibbard RA, Hartman GL. Emotional indicators in human figure drawings of sexually victimized and nonabused children. J Clin Psychol 1990; 46: 211-9.

23. Realmuto GM, Jensen JB, Wescoe S. Specificity and sensitivity of sexually anatomically correct dolls in substantiating abuse: a pilot study. J Am Acad Adolesc Psychol 1990; 29: 743-6.

24. Ministério da Saúde. Secretaria de Políticas de Saúde. Prevenção e tratamento dos agravos resultantes da violência sexual contra mulheres e adolescentes: norma técnica. Brasília, DF: Ministério da Saúde; 1999.

25. De San Lazaro C. Making paediatric assessment in suspected sexual abuse a therapeutic experience. Arch Dis Child 1995; 73: 174-6.

26. American Professional Society on the Abuse Children (APSAC). Child maltreatment. [on line]. URL: http://www. apsac.org [14 jun 2000].

27. Gabby T, Winkleby MA, Boyce, T, Fisher DL, Lancaster A, Sensabaugh, DC. Sexual abuse of children: the detection of semen on skin. Am J Dis Child 1992; 146: 700-3.

28. Deblinger E, McLeer S, Henry D. Cognitive behavioral treatment for sexually abused children suffering posttraumatic stress: preliminary findings. J Am Acad Child Adolesc Psychol 1990; 29: 747-52.

29. Muzychka M. Physicians must help diagnose, prevent family violence: Newfoundland MDs say. Can Med Assoc J 1994; 151: 362-3.

Recebido em 28 de maio de 2002

Versão final reapresentada em 4 de julho de 2002 Aprovada em 23 de julho de 2002 